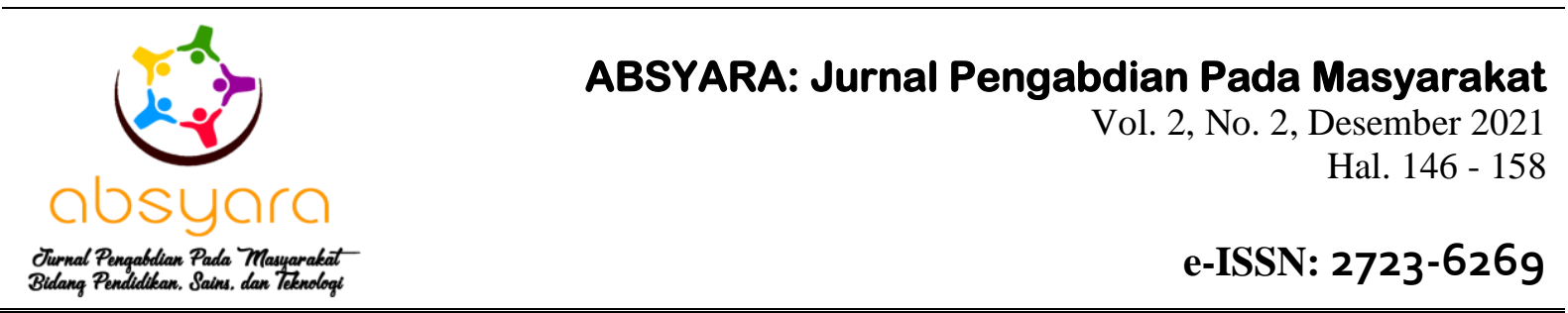

\title{
Pelatihan Uji Kegunaan Website Menggunakan System Usability Scale (SUS)
}

\author{
Rahmat Novrianda Dasmen*¹, Fatoni $^{2}$, Alek Wijaya ${ }^{3}$, Baibul Tujni $^{4}$, Sarita Nabila ${ }^{5}$ \\ rahmat.novrianda.d@ gmail.com*1 \\ ${ }^{1,2,5}$ Program Studi Teknik Komputer, Fakultas Vokasi, Universitas Bina Darma \\ ${ }^{3}$ Program Studi Teknik Informatika, Fakultas Ilmu Komputer, Universitas Bina Darma \\ ${ }^{4}$ Program Studi Komputerisasi Akuntansi, Fakultas Vokasi, Universitas Bina Darma
}

Received: 22 September 2021 Accepted: 18 October 2021 Online Published: 30 December 2021

DOI: 10.29408/ab.v2i2.4031

\begin{abstract}
Abstrak: System Usability Scale (SUS) merupakan salah satu teknik pengujian kegunaan terhadap satu sistem sederhana dengan memanfaatkan skala Likert. Pengujian dan juga analisis kegunaan merupakan salah satu proses penilaian tingkat kepuasan user terhadap sistem atau web. Sehingga tujuan dari kegiatan pengabdian ini adalah untuk melatih pengujian kegunaan website dengan SUS, menggunakan situs web Dukcapil sebagai objek pengujian. Website Dukcapil yang akan dianalisis tingkat kegunaannya sebagai kasus nyata untuk praktik secara langsung. Dalam SUS digunakan sebanyak 10 pernyataan sebagai parameter dalam penilaian kegunaan suatu situs web. Kegiatan ini diikuti oleh 20 orang, terdiri dari mahasiswa Universitas Bina Darma, siswa SMK, serta staf IT dari Dukcapil Kota Palembang. Adapun analisis kegunaan situs web ini bertujuan untuk memberikan penilaian seberapa interaksi user terhadap situs web berjalan dengan baik. Kemudian, hasil penilaian serta analisis ini menghasilkan suatu masukan sebagai acuan untuk pengembangan situs web agar dapat lebih optimal ke depannya. Pada pengujian kegunaan website Dukcapil dalam kegiatan PKM ini, dapat dilihat nilai SUS berada pada skor sebesar 56,125, dengan keterangan "dapat diterima" oleh karena itu, dapat dianalisis website Dukcapil berada di peringkat F yang memiliki kategori pemeringkatan "Good". Dari hasil pelatihan yang dilakukan, dapat diketahui bahwa situs web Dukcapil masih sangat jarang diakses oleh user dikarenakan memberikan informasi yang masih kurang update, fitur yang digunakan masih dalam bentuk beta (masih dalam tahap uji coba), sehingga pengguna atau peserta masih kurang memahami tentang cara penggunaannya. Selain itu, kegiatan ini memberikan pemahaman kepada peserta mengenai uji kegunaan website dengan model SUS.
\end{abstract}

Kata Kunci: Skala Likert; System Usability Scale (SUS); Uji Kegunaan Website

\begin{abstract}
System Usability Scale (SUS) is a usability testing technique for a simple system using a Likert scale. Testing and usability analysis assess user satisfaction with the system or web. So, the purpose of this service activity is to train website usability testing with SUS, using the Dukcapil website as a test object. Dukcapil's website will be analyzed for its usability level as a real case for direct practice. In SUS, ten statements are used as parameters in assessing the usability of a website. This activity was attended by 20 people, including Bina Darma University students, vocational students, and IT staff from the Dukcapil Palembang City. The usability analysis of this website aims to assess how well user interaction with the website is going. Then, the results of this assessment and study produce an input as a reference for website development to be more optimal in the future. In testing the usefulness of the Dukcapil website in this PKM activity, it can be seen that the SUS score is at a score of 56.125, with the category Acceptable. Therefore, it shows that the Dukcapil website is ranked F, with a "Good" rating category. The training results show that the Dukcapil website is still very rarely accessed by users. Because it provides information lacking in updates, the features used are still in beta version (still in the testing phase). Users or participants still do not understand how to use it. In addition, this activity provides participants with an understanding of the website usability test using the SUS model.
\end{abstract}

Keyword: Likert Scale; System Usability Scale (SUS); Usability Test Site 
Dasmen, R. N., Fatoni, F., Wijaya, A., Tujni, B., Nabila, S. (2021) Pelatihan uji kegunaan website menggunakan System Usability Scale (SUS). ABSYARA: Jurnal Pengabdian Pada Masyarakat, 2(2), 146-158. doi:10.29408/ab.v2i2.4031

\section{PENDAHULUAN}

Dinas Kependudukan dan Catatan Sipil (Dukcapil) adalah salah satu instansi pemerintahan yang sangat dibutuhkan sehingga pada masa Pandemi Covid-19 ini dibutuhkan pelayanan Dukcapil secara online. Oleh karena itu, Dukcapil merancang suatu website yang dapat digunakan untuk melayani kebutuhan masyarakat yang berhubungan dengan Dukcapil. Akan tetapi, website Dukcapil ini masih dalam bentuk beta sehingga perlu dilakukan suatu pengujian terhadap kehandalam dari website Dukcapil ini. Usability merupakan suatu parameter yang sangat dibutuhkan sehingga dapat memengaruhi satu website dapat bertahan atau tidaknya, yang mana jika tingkat usability tinggi, maka akan meningkatkan jumlah pengunjung website tersebut (Borkowska \& Jach, 2017). Pada umumnya user sangat menginginkan suatu informasi secara cepat dan juga sesuai seperti yang mereka harapkan, sehingga jika website tidak dapat diakses dengan cepat serta memberikan informasi yang tidak sesuai dengan kebutuhan user maka pengunjung website tersebut pun akan sangat sedikit ataupun user dapat beralih ke website lainnya.

Terdapat beberapa cara yang bisa digunakan dalam menilai kehandalan dari suatu sistem seperti dengan melakukan penerapan penggunaan fitur yang dimiliki website dapat diakses dengan mudah dan juga memenuhi kebutuhan pengguna, contohnya situs web tersebut dapat dibuka oleh pengguna kapan saja dan dimana saja. Pengujian usability adalah salah satu bagian yang sangat penting untuk website, yang mana dalam pengujian tersebut dilakukan penilaian terhadap respon pengguna dalam penggunaan suatu system sesuai dengan tujuan dan juga menilai tingkat kepuasan user terhadap sistem tersebut. Selain itu, bagian ini menjelaskan tentang kesesuaian GUI dari sistem atau situs web dengan kebutuhan dan ketertarikan dari pengguna (Alqahtani, 2019).

Adapun cara menilai suatu situs web memiliki tingkat kualitas yang tinggi adalah dengan menguji pada beberapa bagian yang berkaitan dengan kualitas dari suatu situs web. Pada pengujian usability, terdapat beberapa pilihan metode untuk melakukan pengujian dan evaluasi terhadap kualitas dari suatu situs web yaitu sebagai berikut (Rohman \& Kurniawan, 2017): 1) Survei secara langsung dilokasi, 2) Pengujian A/B, 3) Melacak dengan mata, 3) Pengujian dengan pemahaman yang mendalam, 4) Pengujian warna dasar, 5) Heuristic Evaluation, 7) System Usability Scale (SUS)

Teknik pelacakan dengan mata merupakan salah satu teknik yang tepat dipergunakan untuk mengukur usability dan juga dapat dijadikan sebagai bukti yang bersifat kuantitatif tentang kehandalan dari website tersebut (Suandi, Sibagariang, Amalia, \& Firdaus, 2021). Pentingnya pengujian usability suatu web agar website tersebut dapat selalu melakukan perbaikan-perbaikan guna kepuasa pengguna (Amri, dkk., 2018). Selain itu, terdapat beberapa parameter dari proses uji usability yang belum bisa dinilai yaitu parameter kepuasan pengguna terhadap penggunaan website secara menyeluruh, sehingga teknik pelacakan dengan mata memerlukan metode tambahan (Salamah, 2019). Oleh sebab itu, teknik yang cocok untuk ditambahkan pada teknik pelacakan dengan mata adalah dengan menggunakan teknik kuesioner sehingga dapat memperoleh tingkat kepuasan user terhadap situs web tersebut (Subiyakto \& Wijaya, 2018).

Sitrasmilaus web memberikan fungsi penting pada kehidupan sehari-hari, sehingga dalam pelaksanaan kegiatan PKM ini diberikan contoh praktek pengujian situs web Dukcapil menggunakan metode SUS. Alamat situs web Dukcapil yaitu dukcapil.online digunakan 
sebagai wadah informasi, serta sebagai sarana komunikasi dan pemberian saran. Akan tetapi, dalam masa pandemi Covid-19 ini diterapkan berbagai pembatasan gerak masyarakat sehingga Dukcapil merancang situs web dengan tujuan agar masyarakat tetap bisa melakukan pengurusan berkas terkait dengan Capil secara daring (dalam jaringan) memanfaatkan situs web Dukcapil ini. Dalam waktu ini, situs web dukcapil.online terus dilakukan penambahan fitur yang dapat diakses melalui menu utama pada demo.dukcapil.online serta terdapat pemberitahuan bahwa masih dalam kondisi demo aplikasi. Dengan kondisi tersebut, maka dapat menjadi studi kasus pada kegiatan PKM ini dalam menilai dan melakukan evaluasi terhadap situs web Dukcapil yaitu dukcapil.online dengan memanfaatkan metode SUS. Hasil dari kegiatan PKM ini dapat menjadi rekomendasi kepada pengembang situs web Dukcapil sebagai tolak ukur dalam melakukan revisi serta pengembangan situs web tersebut.

\section{METODE PELAKSANAAN}

\section{Waktu dan Lokasi}

Adapun pelaksanaan kegiatan PKM ini dimulai dari tanggal 16 hingga 17 April 2021 memanfaatkan aplikasi Zoom Meeting dan diikuti oleh 20 orang peserta yang berasal dari dari mahasiswa Universitas Bina Darma, siswa SMK, serta staff IT dari Dukcapil Kota Palembang.

\section{Prosedur pelaksanaan}

Dalam proses pelaksanaan kegiatan PKM ini membutuhkan tahapan-tahapan sehingga pelaksanaannya dapat berjalan sesuai dengan tujuan, sehingga pada kegiatan PKM ini dimanfaatkan Direct Action (Dasmen, Putra, Rasmila, \& Ibadi, 2021). Metode ini merupakan metode yang dapat menggambarkan beberapa kondisi secara bersamaan sehingga dapat digunakan untuk evaluasi serta pengembangan sesuai kebutuhan (Rasmila \& Amalia, 2019). Di bawah ini dapat dilihat merupakan tahapan-tahapan yang terdapat dalam metode Direct Action (Rasmila, dkk., 2021):

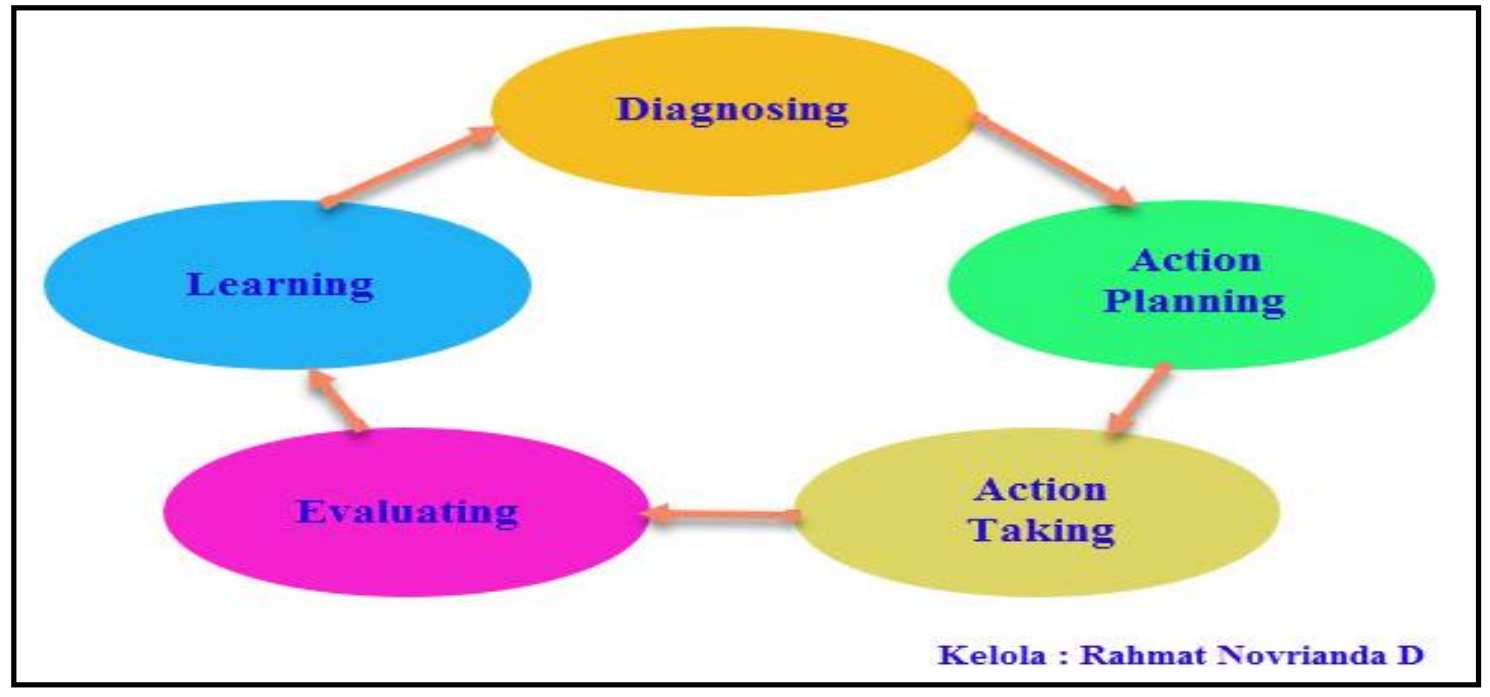

Gambar 1. Metode Direct Action (Dasmen \& Rasmila, 2019)

Pada metode pelaksanaan yang digunakan yaitu Direct Action ataupun aksi secara langsung, yang mana dimaksudkan agar hasil dari kegiatan PKM dapat langsung dipahami serta dipraktekan oleh peserta Pelatihan. Adapun pada kegiatan PKM ini, diberikan juga 
beberapa pertanyaan sebagai uji pemahaman peserta Pelatihan, yang mana pertanyaan yang sama diberikan sebelum dan sesudah kegiatan Pelatihan dilaksanakan. Selain itu, parameter lain untuk mengetahui bahwa kegiatan PKM dapat diterima serta memberikan manfaat bagi Pesertanya adalah dengan melihat hasil analisis peserta terhadap kasus pengujian kehandalan website Dukcapil.

\section{HASIL DAN PEMBAHASAN}

\section{HASIL}

Dari hasil jawaban peserta terhadap pertanyaan yang diberikan sebelum serta sesudah pelaksanaan PKM, diketahui bahwa sudah $85 \%$ peserta yang memahami serta dapat mempraktekan hasil Pelatihan yang diperolehnya. Selain itu, dari hasil analisis yang dibuat oleh peserta berkaitan dengan Usability Testing website Dukcapil, juga dapat dilihat bahwa staf Dukcapil sudah dapat menentukan tingkat kehandalan ataupun kondisi website Dukcapil, sehingga staf Dukcapil dapat mengambil keputusan untuk perbaikan serta pengembangan website dukcapil.online agar sesuai dengan kebutuhan pengguna ataupun masyarakat. Pelaksanaan kegiatan PKM ini memanfaatkan media Live Zoom Meeting, yang mana untuk sampel praktek menggunakan website Dukcapil tersebut serta peserta pelatihan dari staf Dukcapil dan Mahasiswa Universitas Bina Darma seperti yang dapat dilihat pada gambar 2 di bawah ini:

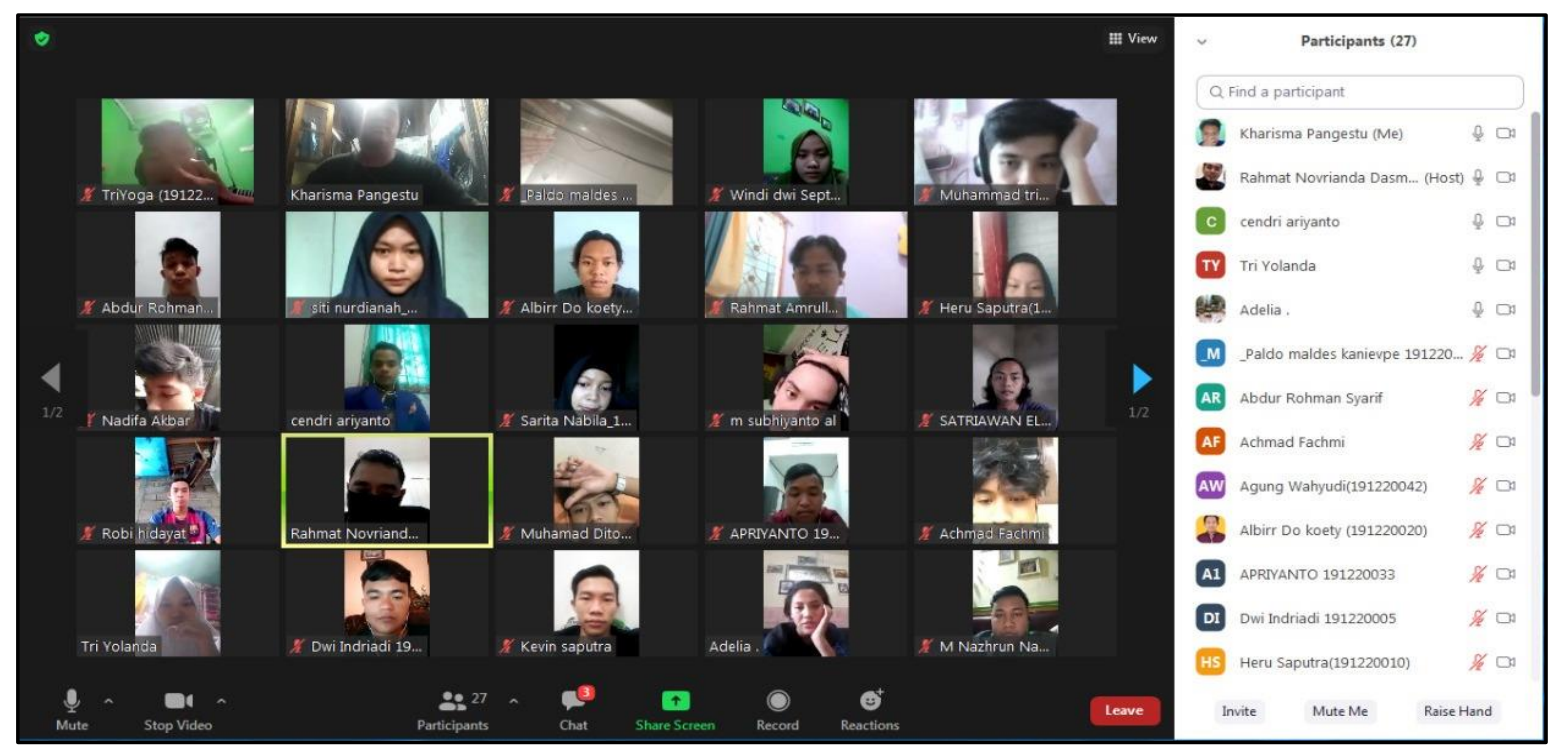

Gambar 2. Pelaksanaan PKM melalui media Live Zoom Meeting

Metode SUS merupakan salah satu metode pengujian usability untuk system sederhana yang mengacu pada skala Likert. Adapun responden akan dihadapkan dengan beberapa pertanyaan kuesioner dengan pernyataan dari Sangat Setuju hingga Sangat Tidak Setuju menggunakan 5 skala yang masing-masing memiliki point 1. 
Tabel 1. Rancangan Kuesioner SUS menurut Brooke

\begin{tabular}{|c|c|c|c|c|c|c|}
\hline No. & Pertanyaan & STS & TS & RG & $\mathbf{S}$ & SS \\
\hline 1. & Sistem ini akan saya gunakan lagi & & & & & \\
\hline 2. & Saya merasa sulit menggunakan sistem ini & & & & & \\
\hline 3. & Saya merasa sistem ini mudah digunakan & & & & & \\
\hline 4. & $\begin{array}{l}\text { Dibutuhkan bantuan orang lain ataupun teknisi } \\
\text { dalam mengakses sistem ini }\end{array}$ & & & & & \\
\hline 5. & $\begin{array}{l}\text { Saya merasa fasilitas dalam sistem ini telah } \\
\text { berjalan sesuai fungsinya }\end{array}$ & & & & & \\
\hline 6. & $\begin{array}{l}\text { Dalam sistem ini terdapat banyak hal yang tak } \\
\text { serasi atau tak konsisten }\end{array}$ & & & & & \\
\hline 7. & $\begin{array}{l}\text { Saya merasa sistem ini akan cepat dipahami cara } \\
\text { penggunaannya oleh orang lain }\end{array}$ & & & & & \\
\hline 8. & $\begin{array}{l}\text { Saya merasa sistem ini masih menimbulkan } \\
\text { kebingungan }\end{array}$ & & & & & \\
\hline 9. & $\begin{array}{l}\text { Tidak ada halangan yang saya rasakan dalam } \\
\text { mengakses sistem ini }\end{array}$ & & & & & \\
\hline 10. & $\begin{array}{l}\text { Saya wajib membiasakan diri terlebih dahulu } \\
\text { sebelum mengakses sistem ini }\end{array}$ & & & & & \\
\hline
\end{tabular}

Keterangan:

STS: Sangat Tidak Setuju

TS: Tidak Setuju

RG: Ragu-ragu

S: Setuju

SS: Sangat Setuju

SUS merupakan metode yang dikemukakan oleh John Brooke pada tahun 1986, yang mana metode SUS sangat sering digunakan sebagai teknik penilaian usability dan menyumbangkan banyak keuntungan pada masa itu. Adapun keuntungan yang diperoleh adalah sebagai berikut (Rafif, Latuconsina, \& Dinimaharawati, 2020) : 1) Metode SUS merupakan metode yang mudah dipergunakan, yang memiliki hasil dalam point $0-100 ; 2$ ) Metode SUS sangat mudah difungsikan, yang mana dalam perhitungannya tidak membutuhkan rumus yang kompleks; 3) Metode SUS merupakan metode yang gratis atau tidak berbayar; 4) Metode SUS diyakini valid dan reliable, walau pada kenyataannya hanya membutuhkan sampel yang tidak banyak.

SUS menyiapkan sebanyak 10 pernyataan dengan pilihan jawaban dari skala 1-5 untuk responden. Adapun pernyataan yang diberikan berkaitan dengan situs web yang akan dinilai, dimana responden dapat memilih Sangat Tidak Setuju hingga Sangat Setuju terhadap pernyataan yang diberikan, yang mana skala 1 adalah "Sangat Tidak Setuju (STS)" dan skala 5 adalah "Sangat Setuju (SS)". SUS akan menyajikan nilai yang merupakan hasil penjumlahan dari parameter fungsi website yang sedang diuji. Adapun kalkulasi pengujian dengan metode SUS memiliki cara yang lain daripada yang lain mengikuti beberapa aturan yang diterapkan 
pada metode SUS. Oleh karena itu, aturan kalkulasi point dari respon kuesioner yaitu 1) Dalam setiap pernyataan bernomor ganjil, point dari jawaban responden akan dilakukan pengurangan 1 point; 2) Dalam setiap pernyataan bernomor genap, hasil akhir penjumlahannya akan dilakukan pengurangan dengan point pernyataan yang didapat oleh responden; 3) Hasil akhir point SUS yang telah dijumlahkan dari setiap point-nya akan dilakukan perkalian dengan 2,5.

Situs web Dukcapil dilengkapi dengan navigasi bar pada posisi atas yang berisikan judul situs web pada bagian kiri yang dilengkapi dengan 2 button pada bagian kanan serta terdapat suatu jumbotron yang memiliki tombol "click to action" serta tampilan terakhir pada bagian bawah terdapat informasi webapp yang digunakan. Selain itu, terdapat hardware yang diperlukan yaitu seperti laptop dan mobile celullar. Kemudian, software yang diperlukan yaitu Google Chrome ataupun Mozilla. User yang dipilih sebagai sampel yang merupakan wakil dari setiap user yang ada (Fadlilah, 2015). Adapaun pada pengujian menggunakan metode SUS ini menggunakan sampel yang merupakan user aktif yaitu staff Dukcapil dan Mahasiswa Universitas Bina Darma sejumlah 20 orang responden.

Berikut ini merupakan langkah perhitungan usability memanfaatkan SUS, yang terdapat 10 pernyataan dengan pilihan jawaban berpedoman pada skala likert dengan skor 1 sampai 5. Selanjutnya, jawaban kuesioner dari responden dihitung menggunakan beberapa aturan yang dijelaskan pada pembahasan sebelumnya. Berikut ini rekap jawaban dari 20 responden:

Tabel 2. Hasil Jawaban Responden

\begin{tabular}{|c|c|c|c|c|c|c|c|c|c|c|}
\hline Responden & Q1 & Q2 & Q3 & Q4 & Q5 & Q6 & Q7 & Q8 & Q9 & Q10 \\
\hline 1. & 4 & 5 & 2 & 4 & 3 & 5 & 3 & 4 & 2 & 4 \\
\hline 2. & 3 & 3 & 3 & 3 & 3 & 3 & 3 & 3 & 3 & 3 \\
\hline 3. & 4 & 2 & 5 & 1 & 4 & 1 & 5 & 1 & 5 & 5 \\
\hline 4. & 5 & 2 & 4 & 1 & 4 & 1 & 5 & 1 & 5 & 2 \\
\hline 5. & 4 & 3 & 3 & 2 & 4 & 2 & 3 & 2 & 4 & 3 \\
\hline 6. & 3 & 3 & 3 & 2 & 4 & 2 & 4 & 3 & 3 & 5 \\
\hline 7. & 3 & 5 & 4 & 5 & 1 & 2 & 3 & 2 & 5 & 2 \\
\hline 8. & 5 & 1 & 3 & 2 & 1 & 5 & 3 & 4 & 2 & 4 \\
\hline 9. & 2 & 4 & 1 & 5 & 2 & 4 & 3 & 2 & 5 & 2 \\
\hline 10. & 5 & 4 & 3 & 2 & 1 & 3 & 5 & 2 & 4 & 1 \\
\hline 11. & 5 & 3 & 1 & 2 & 4 & 3 & 5 & 4 & 2 & 3 \\
\hline 12. & 5 & 4 & 3 & 2 & 1 & 3 & 4 & 5 & 3 & 2 \\
\hline 13. & 5 & 3 & 5 & 4 & 2 & 1 & 3 & 2 & 5 & 4 \\
\hline 14. & 5 & 5 & 4 & 3 & 4 & 3 & 4 & 4 & 3 & 5 \\
\hline 15. & 1 & 1 & 3 & 5 & 2 & 1 & 3 & 1 & 2 & 5 \\
\hline 16. & 5 & 4 & 3 & 4 & 2 & 2 & 4 & 5 & 3 & 1 \\
\hline 17. & 5 & 4 & 5 & 3 & 1 & 2 & 3 & 5 & 2 & 1 \\
\hline 18. & 1 & 1 & 4 & 3 & 3 & 4 & 4 & 4 & 4 & 2 \\
\hline 19. & 5 & 4 & 3 & 1 & 3 & 5 & 4 & 2 & 4 & 1 \\
\hline 20. & 5 & 3 & 4 & 2 & 2 & 2 & 4 & 3 & 1 & 2 \\
\hline
\end{tabular}


Setelah direkap jawaban dari responden, maka langkah selanjutnya adalah dengan menginplementasikan aturan pertama dari SUS seperti terlihat pada Tabel 3 di bawah ini:

Tabel 3. Hasil respon dari Penerapan aturan pertama SUS

\begin{tabular}{ccccccccccc}
\hline Respoden & Q1 & Q2 & Q3 & Q4 & Q5 & Q6 & Q7 & Q8 & Q9 & Q10 \\
\hline 1. & $4-1$ & 5 & $2-1$ & 4 & $3-1$ & 5 & $3-1$ & 4 & $2-1$ & 4 \\
2. & $3-1$ & 3 & $3-1$ & 3 & $3-1$ & 3 & $3-1$ & 3 & $3-1$ & 3 \\
3. & $4-1$ & 2 & $5-1$ & 1 & $4-1$ & 1 & $5-1$ & 1 & $5-1$ & 5 \\
4. & $5-1$ & 2 & $4-1$ & 1 & $4-1$ & 1 & $5-1$ & 1 & $5-1$ & 2 \\
5. & $4-1$ & 3 & $3-1$ & 2 & $4-1$ & 2 & $3-1$ & 2 & $4-1$ & 3 \\
6. & $3-1$ & 3 & $3-1$ & 2 & $4-1$ & 2 & $4-1$ & 3 & $3-1$ & 5 \\
7. & $3-1$ & 5 & $4-1$ & 5 & $1-1$ & 2 & $3-1$ & 2 & $5-1$ & 2 \\
8. & $5-1$ & 1 & $3-1$ & 2 & $1-1$ & 5 & $3-1$ & 4 & $2-1$ & 4 \\
9. & $2-1$ & 4 & $1-1$ & 5 & $2-1$ & 4 & $3-1$ & 2 & $5-1$ & 2 \\
10. & $5-1$ & 4 & $3-1$ & 2 & $1-1$ & 3 & $5-1$ & 2 & $4-1$ & 1 \\
11. & $5-1$ & 3 & $1-1$ & 2 & $4-1$ & 3 & $5-1$ & 4 & $2-1$ & 3 \\
12. & $5-1$ & 4 & $3-1$ & 2 & $1-1$ & 3 & $4-1$ & 5 & $3-1$ & 2 \\
13. & $5-1$ & 3 & $5-1$ & 4 & $2-1$ & 1 & $3-1$ & 2 & $5-1$ & 4 \\
14. & $5-1$ & 5 & $4-1$ & 3 & $4-1$ & 3 & $4-1$ & 4 & $3-1$ & 5 \\
15. & $1-1$ & 1 & $3-1$ & 5 & $2-1$ & 1 & $3-1$ & 1 & $2-1$ & 5 \\
16. & $5-1$ & 4 & $3-1$ & 4 & $2-1$ & 2 & $4-1$ & 5 & $3-1$ & 1 \\
17. & $5-1$ & 4 & $5-1$ & 3 & $1-1$ & 2 & $3-1$ & 5 & $2-1$ & 1 \\
18. & $1-1$ & 1 & $4-1$ & 3 & $3-1$ & 4 & $4-1$ & 4 & $4-1$ & 2 \\
19. & $5-1$ & 4 & $3-1$ & 1 & $3-1$ & 5 & $4-1$ & 2 & $4-1$ & 1 \\
20. & $5-1$ & 3 & $4-1$ & 2 & $2-1$ & 2 & $4-1$ & 3 & $1-1$ & 2 \\
\hline
\end{tabular}

Kemudian, dari hasil yang diperoleh pada Tabel 3 di atas ini dilakukan penerapan aturan kedua dari SUS yang dapat dilihat pada Tabel 4 di bawah ini:

Tabel 4. Hasil Respon Penerapan aturan kedua SUS

\begin{tabular}{ccccccccccc}
\hline Responden & Q1 & Q2 & Q3 & Q4 & Q5 & Q6 & Q7 & Q8 & Q9 & Q10 \\
\hline 1. & $4-1$ & $5-5$ & $2-1$ & $5-4$ & $3-1$ & $5-5$ & $3-1$ & $5-4$ & $2-1$ & $5-4$ \\
2. & $3-1$ & $5-3$ & $3-1$ & $5-3$ & $3-1$ & $5-3$ & $3-1$ & $5-3$ & $3-1$ & $5-3$ \\
3. & $4-1$ & $5-2$ & $5-1$ & $5-1$ & $4-1$ & $5-1$ & $5-1$ & $5-1$ & $5-1$ & $5-5$ \\
4. & $5-1$ & $5-2$ & $4-1$ & $5-1$ & $4-1$ & $5-1$ & $5-1$ & $5-1$ & $5-1$ & $5-2$ \\
5. & $4-1$ & $5-3$ & $3-1$ & $5-2$ & $4-1$ & $5-2$ & $3-1$ & $5-2$ & $4-1$ & $5-3$ \\
6. & $3-1$ & $5-3$ & $3-1$ & $5-2$ & $4-1$ & $5-2$ & $4-1$ & $5-3$ & $3-1$ & $5-5$ \\
7. & $3-1$ & $5-5$ & $4-1$ & $5-5$ & $1-1$ & $5-2$ & $3-1$ & $5-2$ & $5-1$ & $5-2$ \\
8. & $5-1$ & $5-1$ & $3-1$ & $5-2$ & $1-1$ & $5-5$ & $3-1$ & $5-4$ & $2-1$ & $5-4$ \\
9. & $2-1$ & $5-4$ & $1-1$ & $5-5$ & $2-1$ & $5-4$ & $3-1$ & $5-2$ & $5-1$ & $5-2$ \\
\hline
\end{tabular}




\begin{tabular}{llllllllllll}
\hline 10. & $5-1$ & $5-4$ & $3-1$ & $5-2$ & $1-1$ & $5-3$ & $5-1$ & $5-2$ & $4-1$ & $5-1$ \\
11. & $5-1$ & $5-3$ & $1-1$ & $5-2$ & $4-1$ & $5-3$ & $5-1$ & $5-4$ & $2-1$ & $5-3$ \\
12. & $5-1$ & $5-4$ & $3-1$ & $5-2$ & $1-1$ & $5-3$ & $4-1$ & $5-5$ & $3-1$ & $5-2$ \\
13. & $5-1$ & $5-3$ & $5-1$ & $5-4$ & $2-1$ & $5-1$ & $3-1$ & $5-2$ & $5-1$ & $5-4$ \\
14. & $5-1$ & $5-5$ & $4-1$ & $5-3$ & $4-1$ & $5-3$ & $4-1$ & $5-4$ & $3-1$ & $5-5$ \\
15. & $1-1$ & $5-1$ & $3-1$ & $5-5$ & $2-1$ & $5-1$ & $3-1$ & $5-1$ & $2-1$ & $5-5$ \\
16. & $5-1$ & $5-4$ & $3-1$ & $5-4$ & $2-1$ & $5-2$ & $4-1$ & $5-5$ & $3-1$ & $5-1$ \\
17. & $5-1$ & $5-4$ & $5-1$ & $5-3$ & $1-1$ & $5-2$ & $3-1$ & $5-5$ & $2-1$ & $5-1$ \\
18. & $1-1$ & $5-1$ & $4-1$ & $5-3$ & $3-1$ & $5-4$ & $4-1$ & $5-4$ & $4-1$ & $5-2$ \\
19. & $5-1$ & $5-4$ & $3-1$ & $5-1$ & $3-1$ & $5-5$ & $4-1$ & $5-2$ & $4-1$ & $5-1$ \\
20. & $5-1$ & $5-3$ & $4-1$ & $5-2$ & $2-1$ & $5-2$ & $4-1$ & $5-3$ & $1-1$ & $5-2$ \\
\hline
\end{tabular}

Setelah selesai perhitungan dengan menerapkan aturan kedua SUS, maka dilanjutkan dengan mengakumulasi hasil perhitungan dari aturan ke-1 dan aturan ke-2 seperti pada Tabel 5 di bawah ini:

Tabel 5. Hasil Respon aturan ke-1 dan ke-2 SUS

\begin{tabular}{|c|c|c|c|c|c|c|c|c|c|c|}
\hline Responden & Q1 & Q2 & Q3 & Q4 & Q5 & Q6 & Q7 & Q8 & Q9 & Q10 \\
\hline 1. & 3 & 0 & 1 & 1 & 2 & 0 & 2 & 1 & 1 & 1 \\
\hline 2. & 2 & 2 & 2 & 2 & 2 & 2 & 2 & 2 & 2 & 2 \\
\hline 3. & 3 & 3 & 4 & 4 & 3 & 4 & 4 & 4 & 4 & 0 \\
\hline 4. & 4 & 3 & 3 & 4 & 3 & 4 & 4 & 4 & 4 & 3 \\
\hline 5. & 3 & 2 & 2 & 3 & 3 & 3 & 2 & 3 & 3 & 2 \\
\hline 6. & 2 & 2 & 2 & 3 & 3 & 3 & 3 & 2 & 2 & 0 \\
\hline 7. & 2 & 0 & 3 & 0 & 0 & 3 & 2 & 3 & 4 & 3 \\
\hline 8. & 4 & 4 & 2 & 3 & 0 & 0 & 2 & 1 & 1 & 1 \\
\hline 9. & 1 & 1 & 0 & 0 & 1 & 1 & 2 & 3 & 4 & 3 \\
\hline 10. & 4 & 1 & 2 & 3 & 0 & 2 & 4 & 3 & 3 & 4 \\
\hline 11. & 4 & 2 & 0 & 3 & 3 & 2 & 4 & 1 & 1 & 2 \\
\hline 12. & 4 & 1 & 2 & 3 & 0 & 2 & 3 & 0 & 2 & 3 \\
\hline 13 & 4 & 2 & 4 & 1 & 1 & 4 & 2 & 3 & 4 & 1 \\
\hline 14. & 4 & 0 & 3 & 2 & 3 & 2 & 3 & 1 & 2 & 0 \\
\hline 15. & 0 & 4 & 2 & 0 & 1 & 4 & 2 & 4 & 1 & 0 \\
\hline 16. & 4 & 1 & 2 & 1 & 1 & 3 & 3 & 0 & 2 & 4 \\
\hline 17. & 4 & 1 & 4 & 2 & 0 & 3 & 2 & 0 & 1 & 4 \\
\hline 18. & 0 & 4 & 3 & 2 & 2 & 1 & 3 & 1 & 3 & 3 \\
\hline 19. & 4 & 1 & 2 & 4 & 2 & 0 & 3 & 3 & 3 & 4 \\
\hline 20. & 4 & 2 & 3 & 3 & 1 & 3 & 3 & 2 & 0 & 3 \\
\hline
\end{tabular}


Setelah selesai melakukan akumulasi, maka langkah selanjutnya adalah dengan menerapkan aturan ke-3 SUS yang dapat dilihat pada Tabel 6. Selain itu, lanjut dengan perhitungan untuk mencari nilai rata-rata yang dapat dilihat dalam Tabel 7 di bawah ini :

Tabel 6. Hasil Penerapan aturan ketiga SUS

\begin{tabular}{ccccccccccccc}
\hline Responden & Q1 & Q2 & Q3 & Q4 & Q5 & Q6 & Q7 & Q8 & Q9 & Q10 & Jumlah & $\begin{array}{c}\text { Nilai } \\
\text { (Jumlah*2.5) }\end{array}$ \\
\hline 1. & 3 & 0 & 1 & 1 & 2 & 0 & 2 & 1 & 1 & 1 & 12 & 30 \\
2. & 2 & 2 & 2 & 2 & 2 & 2 & 2 & 2 & 2 & 2 & 20 & 50 \\
3. & 3 & 3 & 4 & 4 & 3 & 4 & 4 & 4 & 4 & 0 & 33 & 82,5 \\
4. & 4 & 3 & 3 & 4 & 3 & 4 & 4 & 4 & 4 & 3 & 36 & 90 \\
5. & 3 & 2 & 2 & 3 & 3 & 3 & 2 & 3 & 3 & 2 & 26 & 65 \\
6. & 2 & 2 & 2 & 3 & 3 & 3 & 3 & 2 & 2 & 0 & 22 & 55 \\
7. & 2 & 0 & 3 & 0 & 0 & 3 & 2 & 3 & 4 & 3 & 20 & 50 \\
8. & 4 & 4 & 2 & 3 & 0 & 0 & 2 & 1 & 1 & 1 & 18 & 45 \\
9. & 1 & 1 & 0 & 0 & 1 & 1 & 2 & 3 & 4 & 3 & 16 & 40 \\
$\mathbf{1 0}$ & 4 & 1 & 2 & 3 & 0 & 2 & 4 & 3 & 3 & 4 & 26 & 65 \\
$\mathbf{1 1 .}$ & 4 & 2 & 0 & 3 & 3 & 2 & 4 & 1 & 1 & 2 & 22 & 55 \\
$\mathbf{1 2 .}$ & 4 & 1 & 2 & 3 & 0 & 2 & 3 & 0 & 2 & 3 & 20 & 50 \\
$\mathbf{1 3 .}$ & 4 & 2 & 4 & 1 & 1 & 4 & 2 & 3 & 4 & 1 & 26 & 65 \\
$\mathbf{1 4}$ & 4 & 0 & 3 & 2 & 3 & 2 & 3 & 1 & 2 & 0 & 20 & 50 \\
$\mathbf{1 5 .}$ & 0 & 4 & 2 & 0 & 1 & 4 & 2 & 4 & 1 & 0 & 18 & 45 \\
$\mathbf{1 6 .}$ & 4 & 1 & 2 & 1 & 1 & 3 & 3 & 0 & 2 & 4 & 21 & 52,5 \\
$\mathbf{1 7 .}$ & 4 & 1 & 4 & 2 & 0 & 3 & 2 & 0 & 1 & 4 & 21 & 52,5 \\
$\mathbf{1 8 .}$ & 0 & 4 & 3 & 2 & 2 & 1 & 3 & 1 & 3 & 3 & 22 & 55 \\
$\mathbf{1 9 .}$ & 4 & 1 & 2 & 4 & 2 & 0 & 3 & 3 & 3 & 4 & 26 & 65 \\
$\mathbf{2 0 .}$ & 4 & 2 & 3 & 3 & 1 & 3 & 3 & 2 & 0 & 3 & 24 & 60 \\
\hline & & & & & & & & & & & &
\end{tabular}

Tabel 7. Perhitungan mencari nilai rata - rata

\begin{tabular}{ccccccccccccc}
\hline Responden & Q1 & Q2 & Q3 & Q4 & Q5 & Q6 & Q7 & Q8 & Q9 & Q10 & Jumlah & $\begin{array}{c}\text { Nilai } \\
\text { (Jumlah*2.5) }\end{array}$ \\
\hline 1. & 3 & 0 & 1 & 1 & 2 & 0 & 2 & 1 & 1 & 1 & 12 & 30 \\
2. & 2 & 2 & 2 & 2 & 2 & 2 & 2 & 2 & 2 & 2 & 20 & 50 \\
3. & 3 & 3 & 4 & 4 & 3 & 4 & 4 & 4 & 4 & 0 & 33 & 82,5 \\
4. & 4 & 3 & 3 & 4 & 3 & 4 & 4 & 4 & 4 & 3 & 36 & 90 \\
5. & 3 & 2 & 2 & 3 & 3 & 3 & 2 & 3 & 3 & 2 & 26 & 65 \\
6. & 2 & 2 & 2 & 3 & 3 & 3 & 3 & 2 & 2 & 0 & 22 & 55 \\
7. & 2 & 0 & 3 & 0 & 0 & 3 & 2 & 3 & 4 & 3 & 20 & 50 \\
8. & 4 & 4 & 2 & 3 & 0 & 0 & 2 & 1 & 1 & 1 & 18 & 45 \\
9. & 1 & 1 & 0 & 0 & 1 & 1 & 2 & 3 & 4 & 3 & 16 & 40 \\
10. & 4 & 1 & 2 & 3 & 0 & 2 & 4 & 3 & 3 & 4 & 26 & 65 \\
11. & 4 & 2 & 0 & 3 & 3 & 2 & 4 & 1 & 1 & 2 & 22 & 55 \\
\end{tabular}




$\begin{array}{llllllllllllc}\text { 12. } & 4 & 1 & 2 & 3 & 0 & 2 & 3 & 0 & 2 & 3 & 20 & 50 \\ \text { 13. } & 4 & 2 & 4 & 1 & 1 & 4 & 2 & 3 & 4 & 1 & 26 & 65 \\ \text { 14. } & 4 & 0 & 3 & 2 & 3 & 2 & 3 & 1 & 2 & 0 & 20 & 50 \\ \text { 15. } & 0 & 4 & 2 & 0 & 1 & 4 & 2 & 4 & 1 & 0 & 18 & 45 \\ \text { 16. } & 4 & 1 & 2 & 1 & 1 & 3 & 3 & 0 & 2 & 4 & 21 & 52,5 \\ \text { 17. } & 4 & 1 & 4 & 2 & 0 & 3 & 2 & 0 & 1 & 4 & 21 & 52,5 \\ \text { 18. } & 0 & 4 & 3 & 2 & 2 & 1 & 3 & 1 & 3 & 3 & 22 & 55 \\ \text { 19. } & 4 & 1 & 2 & 4 & 2 & 0 & 3 & 3 & 3 & 4 & 26 & 65 \\ \text { 20. } & 4 & 2 & 3 & 3 & 1 & 3 & 3 & 2 & 0 & 3 & 24 & 60\end{array}$

\section{Rata - Rata}

\section{PEMBAHASAN}

SUS merupakan teknik yang umum digunakan dalam perhitungan usability secara subjektif terhadap penilaian user. Skor SUS itu sendiri merupakan indikator kepuasan user, yang mana skor SUS dapat diartikan sebagai kategori acceptability yang memiliki grade scale serta adjective rating yang terdiri dari kelipatan angka 10. Skala dimulai dari 1 sampai $>10$ termasuk ke dalam kategori rating worst imaginable, skala dimulai dari $>10$ sampai 20 termasuk kategori rating awful, skala dimulai dari 20 sampai $>30$ termasuk kategori rating poor, skala dimulai dari $>30$ sampai $>50$ termasuk ke dalam kategori rating ok, skala dimulai dari >50 sampai >70 termasuk kategori rating good, skala dimulai dari $>70$ sampai $>80$ termasuk ke dalam kategori rating excellent, selanjtnya skala dimulai dari $>80$ sampai $>90$ merupakan kategori rating best imaginable serta pengelompokan ini terlihat dalam gambar 2 berikut ini (Ependi, Kurniawan, \& Panjaitan, 2019):

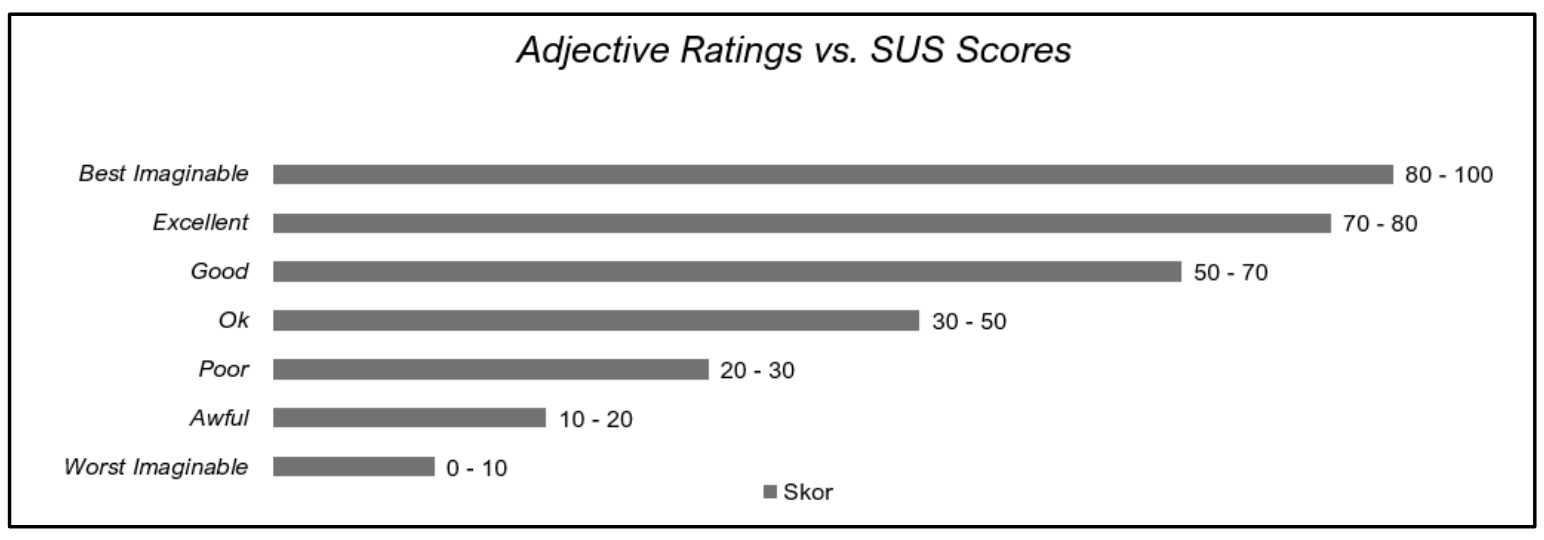

Gambar 3. Skor SUS untuk Adjective rating scale

Kemudian, pengelompokan grade scale, yaitu skala dimulai dari 0 sampai 60 ditampilkan dalam nilai huruf " $F$ ", skala dimulai dari $>60$ sampai 70 ditampilkan dalam nilai huruf "D", skala dimulai dari > 70 sampai 80 ditampilkan dalam nilai huruf "C", skala dimulai dari >80 sampai 90 ditampilkan dalam nilai huruf "B" serta skala dimulai dari >90 sampai 100 ditampilkan dalam nilai huruf "A". Selain itu, pengelompokan acceptability ranges menggunakan skala dimulai dari 0 sampai 60 dipresentasikan "not acceptable" serta skala 
Dasmen, R. N., Fatoni, F., Wijaya, A., Tujni, B., Nabila, S. (2021) Pelatihan uji kegunaan website menggunakan System Usability Scale (SUS). ABSYARA: Jurnal Pengabdian Pada Masyarakat, 2(2), 146-158. doi:10.29408/ab.v2i2.4031

dimulai dari >60 sampai 100 dipresentasikan "acceptable", yang mana dapat dilihat dalam Gambar 3 berikut ini:

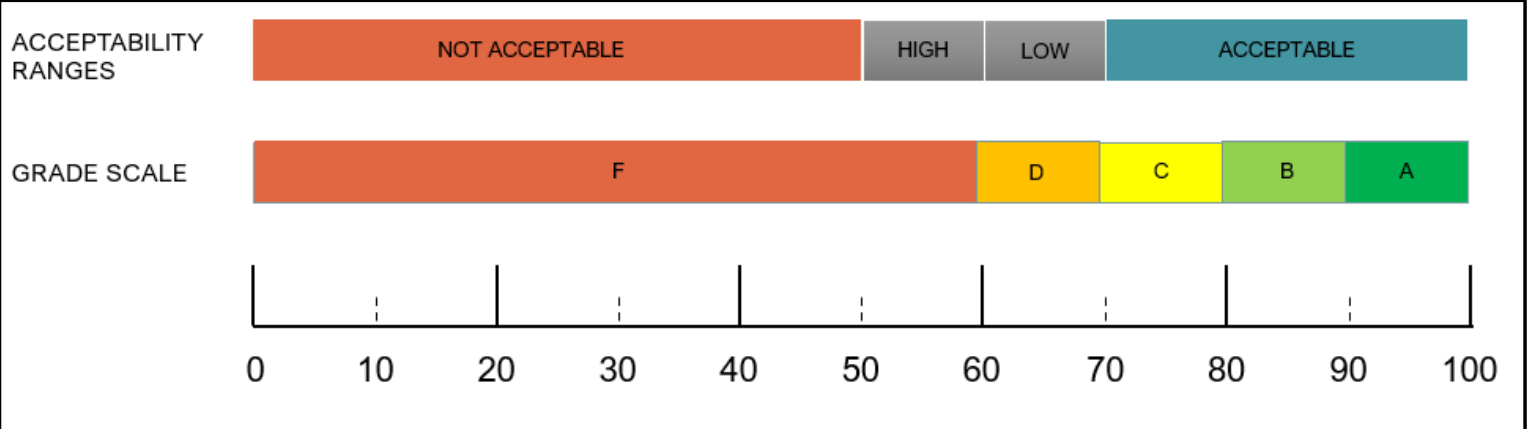

Gambar 4. Skor SUS untuk Grade scale serta acceptability

Hasil perhitungan SUS merupakan parameter apakah sistem tersebut bisa diterima atau tidak oleh user, yang mana agar sistem diterima oleh user maka acceptability range yang diperoleh haruslah lebih dari skor 60 atau skornya haruslah di atas skor 70 sehingga dapat dikategorikan sebagai sistem yang Acceptable. Akan tetapi, pada contoh kasus dalam kegiatan PKM ini menggunakan website Dukcapil, terlihat dari Tabel 7 rata-ratanya sebesar 56,125, yang mana hal ini diartikan bahwa website Dukcapil masih termasuk ke dalam kelompok sistem yang Not Acceptable. Adapun dapat dijelaskan bahwa tampilan serta desain website Dukcapil dapat dikatakan cukup baik, tetapi belum optimal sebagaimana fungsi sistem tersebut seharusnya dan sesuai apa yang diharapkan oleh responden karena sistem ini masih beta. Selain itu, Adjective Rating Scale dari website Dukcapil dapat dikategorikan "Good" serta Grade Scale masih dalam kelompok nilai huruf " $F$ ". Oleh karena itu, hasil dari analisa pada kegiatan PKM ini diartikan bahwa website Dukcapil masih belum bisa diterima pengguna sehingga website Dukcapil masih perlu dilakukan sosialisasi secara menyeluruh kepada masyarakat untuk penggunaannya. Hal ini disebabkan masyarakat pada umumnya tentu akan bingung dengan perubahan pelayanan Dukcapil yang awalnya selalu dilakukan dengan pertemuan secara langsung dalam berbagai pengurusan berkaitan Dukcapil dan berubah dengan menerapkan sistem online melalui media website dukcapil.online. Selain itu, website Dukcapil yang masih dalam versi beta ataupun dalam masa uji coba sehingga dinilai masih sangat banyak kekurangan dari website Dukcapil dalam versi ini. Untuk itu, diberikan masukan dari hasil penilaian serta perhitungan SUS pada kegiatan PKM ini, agar website Dukcapil dengan cepat diperbaiki sesuai kebutuhan user dan tidak lagi dalam versi beta serta memiliki banyak fitur yang berguna dan tak lagi mengalami bug dalam mengaksesnya.

\section{SIMPULAN}

Kegiatan PKM ini dilaksanakan untuk memperkenalkan serta menerapkan System Usability Scale (SUS) untuk mengetahui kehandalan ataupun usability pada suatu website. Adapun pada kegiatan PKM ini digunakan sampel website dari instansi pemerintahan, yaitu Website Dukcapil. Peserta pelatihan yang merupakan staf Dukcapil dan Mahasiswa Universitas Bina Darma diketahui sudah 85\% memahami mengenai SUS yang dilihat dari hasil tes menjawab beberapa pertanyaan berkaitan dengan kegiatan PKM yang diberikan sebelum serta sesudah pelaksanaan kegiatan Pelatihan ini. Kemudian, dari hasil perhitungan SUS terhadap 
website Dukcapil diperoleh rata-rata nilai 56,125. Oleh karena itu, diketahui bahwa website Dukcapil dalam rating "Good" dengan peringkat "F" sehingga belum dapat diterima oleh pengguna ataupun masyarakat. Hal ini memberikan pemahaman kepada staf Dukcapil terhadap kehandalan website Dukcapil, sehingga staf Dukcapil dapat mengambil keputusan dalam perbaikan bahkan pengembangan website dukcapil.online tersebut. Selain itu, setelah pelaksanaan kegiatan PKM ini, staf Dukcapil sudah dapat menganalisis Usability website Dukcapil kedepannya. Selain itu, bagi Mahasiswa Universitas Bina Darma juga memperoleh pengetahuan serta pemahaman terhadap penggunaan SUS. Adapun tim kegiatan PKM juga tetap memberikan wadah agar peserta Pelatihan dapat melakukan diskusi berkaitan dengan penggunaan SUS.

\section{PERNYATAAN PENULIS}

Naskah artikel ini bersifat orisinal dan belum pernah diterbitkan di jurnal mana pun. Hasil dan pembahasan merupakan hasil kegiatan dan kajian yang ditunjang beberapa artikel hasil pengabdian dan penelitian yang telah dilakukan orang lain sebelumnya.

\section{DAFTAR PUSTAKA}

Alqahtani, A. (2019). Usability Testing of Google Cloud Applications: Students' Perspective. Journal of Technology and Science Education, 9(3), 326-339.

Amri, Z., Uska, M. Z., \& Arianti, B. D. D. (2018). Analisis Usability Website Universitas Hamzanwadi terhadap Kepuasan Pengguna dengan Menggunakan User Satisfaction Model. EDUMATIC: Jurnal Pendidikan Informatika, 2(1), 15-23.

Borkowska, A., \& Jach, K. (2017). Pre-testing of polish translation of System Usability Scale (SUS). Information Systems Architecture and Technology: Proceedings of 37th International Conference on Information Systems Architecture and Technology-ISAT 2016-Part I. Springer: Cham.

Dasmen, R. N., \& Rasmila. (2019). Implementasi Raspberry Pi 3 pada Sistem Pengontrol Lampu berbasis Raspbian Jessie. JEPIN (Jurnal Edukasi dan Penelitian Informatika), $5(1), 46-53$.

Dasmen, R. N., Putra, A., Rasmila, \& Ibadi, T. (2021). Pelatihan Online Penerapan Teknologi RADIUS pada PT. Taspen (Persero) Palembang. ABSYARA: Jurnal Pengabdian Pada Masayarakat, 2(1), 94-101.

Ependi, U., Kurniawan, T. B., \& Panjaitan, F. (2019). System Usability Scale vs Heuristic Evaluation: A Review. Simetris: Jurnal Teknik Mesin, Elektro dan Ilmu Komputer, 10(1), 65-74.

Fadlilah, U. (2015). Rancang Bangun Website dan E-Learning di TPQ Al-Fadhillah. Khazanah Informatika: Jurnal Ilmu Komputer dan Informatika, 1(1), 40-43. 
Dasmen, R. N., Fatoni, F., Wijaya, A., Tujni, B., Nabila, S. (2021) Pelatihan uji kegunaan website menggunakan System Usability Scale (SUS). ABSYARA: Jurnal Pengabdian Pada Masyarakat, 2(2), 146-158. doi:10.29408/ab.v2i2.4031

Rafif, M. F., Latuconsina, R., \& Dinimaharawati, A. (2020). Pembangunan Aplikasi Borang Akreditasi Prodi Berbasis Aps 4.0 Sub Kegiatan Pembangunan Front-end. eProceedings of Engineering, 7.

Rasmila, \& Amalia, R. (2019). Sistem Informasi Penentuan Persiapan Stok Obat menggunakan Weight Moving Average. Jurnal SISTEMASI, 8(3), 465-478.

Rasmila, R., Amalia, R., Jemakmun, J., \& Mukti, A. R. (2021). Pelatihan online internet sehat sebagai media pembelajaran bagi siswa-siswi SMK Nurul Huda Pemulutan Barat. ABSYARA: Jurnal Pengabdian Pada Masyarakat, 2(1), 26-31.

Rohman, F., \& Kurniawan, D. (2017). Pengukuran Kualitas Website Badan Nasional Penanggulangan Bencana Menggunakan Metode WebQual 4.0. JITK (Jurnal Ilmu Pengetahuan Dan Teknologi Komputer), 3(1), 31-38.

Salamah, I. (2019). Evaluasi Usability Website Polsri dengan menggunakan System Usability Scale. Jurnal Nasional Pendidikan Teknik Informatika: JANAPATI, 8(3), 176-183.

Subiyakto, A., \& Wijaya, D. J. (2018). Evaluasi Website Badan Pusat Stastistik Menggunakan Metode Usability Testing. Applied Information System and Management (AISM), 1(2), 81-89. 